\title{
Who Benefits From Health System Change?
}

\section{Citation}

Cutler, David M. 2014. “Who Benefits From Health System Change?" JAMA 312 (16) (October 22): 1639. doi:10.1001/jama.2014.13491.

\section{Published Version}

doi:10.1001/jama.2014.13491

\section{Permanent link}

http://nrs.harvard.edu/urn-3:HUL.InstRepos:32306633

\section{Terms of Use}

This article was downloaded from Harvard University's DASH repository, and is made available under the terms and conditions applicable to Other Posted Material, as set forth at http:// nrs.harvard.edu/urn-3:HUL.InstRepos:dash.current.terms-of-use\#LAA

\section{Share Your Story}

The Harvard community has made this article openly available.

Please share how this access benefits you. Submit a story.

Accessibility 


\title{
Who Benefits From Health System Change?
}

\author{
David M. Cutler, PhD
}

The organization of medical care is changing more rapidly now than at any point in the last century. For decades, health care was a cottage industry: physicians practiced

$\leftarrow$

Related articles pages 1644 , 1653 and 1663

facilities, and other health care entities. Those organizations alternately competed and cooperated as part of an informal local health care system.

Recent years have seen the advent of large, integrated, corporate medicine. Today, the typical US city has 3 to 4 integrated health care systems, generally anchored around large hospitals and extending to suburban areas. ${ }^{1}$ These systems are conglomerations of hospitals, primary care and specialist physicians, outpatient facilities, and postacute care facilities. There remains a fringe of unaffiliated institutions and physicians, but the number of such institutions is declining.

Why is this occurring? And who benefits from it? Three reports in this issue of JAMA examine this question. Joynt and colleagues ${ }^{2}$ examined the question of why consolidation is occurring, focusing on the conversion of not-for-profit hospitals to for-profit status. During their study period (20022010), 237 hospitals (5.2\% of their sample) converted from not-for-profit to for-profit status. For each converting hospital, the authors identified up to 3 matched control hospitals based on size category, teaching status, and region. In their primary analysis, they compared clinical and economic outcomes 2 years before conversion to 2 years after conversion and used difference-in-differences models to minimize any temporary economic and clinical outcomes occurring just before the conversion and to identify changes that occurred after a reasonable period.

A central finding of the study by Joynt et al was that hospitals that converted from not-for-profit to for-profit status had very poor financial performance prior to conversion. The typical converting hospital had a patient-based operating margin ([net revenue from patient care and related revenue - total operating expenses]/net revenue from patient care and related revenue) of $-6.6 \%$ and a total margin ([total revenue - total costs]/total revenue), including non-patient care activities, of $-1.2 \%$. Performance at this level is clearly not sustainable. Thus, part of the rationale for conversion is to stabilize cash flow.

Based on the findings of Joynt et al, hospitals converting to for-profit status were successful at this. Between 2 years before and 2 years after conversion, operating margins at converting hospitals increased by $3.2 \%$, and total margins increased by $2.2 \%$. Operating margins remained negative, but the hospital as a whole would break even. This improvement in margins was significantly greater for the converting hospitals than for a set of matched controls.

Joynt et al were not able to determine the factors associated with cash flow improvements, but they did rule out some explanations. The authors showed that neither Medicare reimbursement nor the number of Medicare admissions changed in the converting hospitals, nor did these hospitals experience an abnormal reduction in Medicaid admissions. What are the converting hospitals doing? There are several explanations. First, converting organizations may be able to increase revenue from private payers. Price increases may be possible if converting hospitals joined a large health care system or more inpatient or outpatient referrals could be obtained. Second, the for-profit organization could be better at reducing costs. Billing and insurance-related services can often be streamlined, and wages higher than market levels might be reduced. Third, some costs might simply be shifted to another level in the organization. The debt of the converting hospital may be serviced at the corporate level rather than the hospital level, which would make the hospital's balance sheet look better even in the absence of a reduction in the actual debt. Similarly, some of the "back office" costs (such as for billing services or human resource functions) may be paid for centrally. Differentiating among these explanations is a clear need in evaluating the financial outcomes of for-profit conversions.

Operating losses are not the only explanation for the recent surge in organizational changes, nor is switching to forprofit status the only form of change occurring. Health care entities that provide medical care are consolidating to raise capital for investment in facilities and equipment (the for-profit acquisitions of Detroit Medical Center and Caritas Christi in Boston both involved promises of new investment); to take advantage of economies of scale, such as in buying and maintaining information technology; to negotiate risk-based contracts with insurers; and to develop deeper referral networks in markets with declining inpatient admissions. The multifactorial nature of consolidation suggests it almost certainly will continue.

A second piece of the consolidation puzzle is who benefits from consolidation. The reports in this issue of JAMA by Robinson and Miller ${ }^{3}$ and by Baker and colleagues ${ }^{4}$ suggest that health care organizations and perhaps physicians benefit, in the form of higher prices. Robinson and Miller examined total spending for more than 4.5 million patients in California physician organizations owned by physicians, by local hospitals, or by multihospital systems. Using total medical spending data from 2009-2012, the authors estimated that medical spending was $10.3 \%$ higher in organiza- 
tions owned by local hospitals and $19.8 \%$ higher in organizations owned by multihospital systems in comparison with physician-owned organizations. Baker et al used national data to address a related question. Using Medicare data, the authors grouped physicians into organizations based on the tax IDs under which they bill, allowing the authors to characterize the physician marketplace in each area along the continuum from more to less concentrated. After merging the physician consolidation data with a sample of medical records for nearly 50 million people nationally and examining how consolidation was related to reimbursement for a new or established office visit, Baker et al estimated that reimbursement for these outpatient services ranged from $5 \%$ to $15 \%$ higher in the most concentrated areas compared with the least concentrated areas.

The reports by by Robinson and Miller and by Baker et al have different strengths and weaknesses. Robinson and Miller had good information on the organizational structure of the physician practices they examined. In contrast, the tax ID used by Baker et al is a less precise measure of physician organization. Physicians may bill under multiple organizations, depending on the contract and insurer. However, Baker et al used a stronger spending measure; their prices reflect a specific delivered service. Robinson and Miller, in contrast, used a measure of spending that could vary with the degree of illness of patients and thus may reflect differences in the underlying patient population rather than by physician organization ownership alone.

However, both studies have limitations. The primary weakness of each report is the cross-sectional nature of the analysis. It is possible that high costs lead physicians and other health care practitioners to merge their services. Pressure from payers to reduce spending is likely greater in these high-cost areas, for example, and consolidation may offer an attractive solution. Alternatively, factors such as the presence of academic medical centers may lead to a different organization of care and different overall levels of spending. Some evidence for this view is provided by Baker et al, who showed that the relationship between consolidation and price was much smaller when looking within states-ie, when including state fixed effects in the modelthan when looking at all variation, whether within states or across states. Factors that vary at the state level are associated with private prices, not just local consolidation.

Baker et al recognize and partially address the issue of causality and secular change using time series data. Specifically, they related changes in prices between 2003 and 2010 to both the level of consolidation in 2002 (when contracts for 2003 would likely have been written), as well as to the change in consolidation over time. Their analysis showed that prices increased more in areas that were less competitive originally and, for some specialties, that increases in concentration were associated with increases in prices. These results are highly sensitive to specialty and specification, however, and so should not be treated as strongly as their cross-sectional results.

Although reverse causation and omitted variables are a concern, these factors are unlikely to explain all of the results, particularly when viewed in the context of prior related work. An extensive literature on hospital consolidation and spending uniformly shows that hospital mergers are associated with greater spending. ${ }^{5-7}$ The finding is so consistent that it would be surprising if it were different for physician consolidation.

Consolidation can affect more than spending. However, the nonprice consequences of consolidation have been much less studied than the price consequences. Quality is a clear area of concern. Neither Robinson and Miller nor Baker et al examined any quality aspects of consolidation. Joynt et al examined the association between for-profit conversion and processes of care (such as using appropriate medications for patients with myocardial infarction), nurse staffing ratios, and mortality rates. They showed no differential changes in quality between converting and nonconverting hospitals. This can be taken as a good sign (ie, becoming a for-profit hospital does not worsen outcomes) or a bad sign (ie, improving financial performance does not lead to better outcomes). The results reported by Joynt et al are consistent with some other research, ${ }^{8}$ although not all. Another set of studies has shown that forprofit hospitals are more likely to invest in profitable services and to avoid unprofitable services than are not-for-profit hospitals. ${ }^{9}$ This aspect of operations was not studied by Joynt et al. Beyond what Joynt et al measured, other natural measures of quality include investment in services such as electronic medical records and decision support software, coordination between inpatient and outpatient settings, resources devoted to uncompensated care (both hospital and physician), and time spent in teaching or medical research.

Along with quality, it would be valuable for studies to measure efficiency. Even though consolidating institutions may increase prices, that does not mean that their underlying costs have increased. Instead, it may be that consolidating institutions are more efficient, and that they pocket the difference between higher prices and lower underlying costs. A hospital that owns physician practices may coordinate discharges more appropriately, leading to shorter lengths of stay, even as it charges more for each admission. Resource use is not measured in any of the 3 studies reported in this issue, nor has the literature generally differentiated between resource use and reimbursement. However, the idea behind many of the policies contained within the Affordable Care Act is that integration will lead organizations to become more efficient, and this efficiency will ultimately appear as lower prices. Initial evidence from the Medicare Accountable Care Organization program reveals cost savings for many institutions, most of which are large organizations of the type considered in these studies. ${ }^{10}$ Along with quality changes, understanding the resource implications of consolidation is a key research area.

Another important issue in evaluating these results is the payment environment in which these systems are operating. Small physician practices and hospitals generally are not particularly savvy about the details of reimbursement. In contrast, large systems can devote much more time and resources to learning about reimbursement systems and how to respond to them. The implication is that consolidation may increase the sensitivity of health care expenditures to environmental conditions. The data from the 3 studies reported in this 
issue of JAMA are all from the period when payments were largely on a fee-for-service basis and patient cost sharing was relatively low. These findings may not necessarily translate to the current rapidly changing environment, in which payments are increasingly rewarded on a value basis, not a volume basis, and in which patients have significant cost sharing for services received. ${ }^{11}$ Such a payment system could lead to more systematic cost savings.
The experience so far is that consolidation has been good for many health care organizations and entities and for many clinicians and practitioner groups, with little clarity on how it has affected patients. Understanding how consolidation is related to resource use and quality of care, and how consolidated institutions will change in a changing health care system, will be fundamental in measuring the winners and losers in the new organization of care.

\section{ARTICLE INFORMATION}

Author Affiliations: Harvard University, Cambridge, Massachusetts; National Bureau of Economic Research, Cambridge, Massachusetts.

Corresponding Author: David M. Cutler, PhD, National Bureau of Economic Research, 1050 Massachusetts Ave, Cambridge, MA 02138 (dcutler@fas.harvard.edu).

Conflict of Interest Disclosures: The author has completed and submitted the ICMJE Form for Disclosure of Potential Conflicts of Interest and reported receiving grants from the National Institutes of Health during the conduct of the study; receiving nonfinancial support from the Alliance for Aging Research, Demos: A Network for Ideas and Action, University of Arizona, University of Missouri-Kansas City, Intermountain Healthcare, Kaiser Permanente, JAMA, US Senate, Partners Healthcare, Princeton University, New Jersey Association of Mental Health and Addiction Agencies, Spinemark, US Department of Health \& Human Services, The Advanced Medical Technology Association, Health Policy Commission (Commonwealth of Massachusetts), University of Chicago, Health Affairs, the National Institutes of Health, DuPont Children's Hospital, Symposium on US Sustainable Health, National Bureau of Economic Research, Institute of Medicine, Georgia State University, Federal Reserve Bank Atlanta, The Commonwealth Fund, Princeton University, Brookings Institute, and Parenteral Drug Association; receiving personal fees and nonfinancial support from Novartis Princeton, MedForce, VHA, International Monetary Fund,
National Council and Community Behavioral Healthcare, Delaware Health Sciences Alliance, Dartmouth College, Healthcare Billing and Management Association, Cadence Health, Pompeu Fabra University, AON Hewitt, American Health Lawyers Association, UBS, Aetna, Toshiba Ernst and Young, Yale University, and New York University; and receiving personal fees from Healthcare Financial Management Association, New York City Health and Hospitals Corporation, Robert W. Baird \& Co, Bank of America Webinar, Mathematica, and Fidelity Scientific Advisory Board, outside the submitted work.

\section{REFERENCES}

1. Cutler DM, Scott Morton F. Hospitals, market share, and consolidation. JAMA. 2013;310(18): 1964-1970.

2. Joynt KE, Orav EJ, Jha AK. Association between hospital conversions to for-profit status and clinical and economic outcomes. JAMA. doi:10.1001/jama .2014.13336.

3. Robinson JC, Miller K. Total expenditures per patient in hospital-owned and physician-owned physician organizations in California. JAMA. doi:10 .1001/jama.2014.14072.

4. Baker LC, Bundorf MK, Royalty AB, Levin Z. Physician practice competition and prices paid by private insurers for office visits. JAMA. doi:10.1001 /jama.2014.10921.

5. Gaynor M, Town R. The Impact of Hospital Consolidation-Update. Robert Wood Johnson Foundation website. http://www.rwjf.org/content /dam/farm/reports/issue_briefs/2012/rwjf73261. June 2012. Accessed September 25, 2014.

6. Murray R, Delbanco SF. Provider Market Power in the U.S. Health Care Industry: Assessing Its Impact and Looking Ahead. Catalyst for Payment Reform website. http://www.catalyzepaymentreform.org /images/documents/Market_Power.pdf. 2012. Accessed September 22, 2014.

7. Health Care Industry Consolidation. Hearing Before the Subcommittee on Health of the Committee on Ways and Means, 112th Cong, 1st Sess (2011) (testimony of Martin Gaynor, Carnegie Mellon University). http://waysandmeans.house.gov /uploadedfiles/gaynor_testimony_9-9-11_final.pdf. Accessed September 22, 2014.

8. Sloan F. Not-for-profit ownership and hospital behavior. In: Culyer AJ, Newhouse JP, eds. Handbook of Health Economics. Amsterdam: North-Holland; 2000.

9. Horwitz JR. Making profits and providing care: comparing nonprofit, for-profit, and government hospitals. Health Aff (Millwood). 2005;24(3):790801.

10. L \& M Policy Research. Evaluation of CMMI Accountable Care Organization Initiatives: Effect of Pioneer ACOs on Medicare Spending in the First Year. L \& M Policy Research website. http://innovation.cms.gov/Files/reports /PioneerACOEvalReport1.pdf. November 13, 2013. Accessed September 22, 2014.

11. Dafny L. Hospital industry consolidation-still more to come? N Engl J Med. 2014;370(3):198-199. 